\title{
Effective Use of Graduate Students as Teaching Assistants in Undergraduate Engineering Education
}

\author{
Dr. Janna Rosales \\ Assistant Professor \\ Faculty of Engineering and Applied Science \\ Memorial University \\ jrosales@mun.ca \\ Darlene Spracklin-Reid, P.Eng \\ Senior Instructional Designer \\ Memorial University \\ darlenesr@mun.ca
}

\author{
Susan Caines, P.Eng. M.Eng \\ Doctoral Candidate, Process Engineering \\ Faculty of Engineering and Applied Science \\ Memorial University \\ susan.caines@mun.ca
}

\begin{abstract}
Undergraduate Engineering Education can be significantly enhanced through the effective use of Teaching Assistants. Traditionally, Teaching Assistants have been viewed as support for the instructor, but as student-centred learning models take more precedence, the role of the Teaching Assistant is changing to adapt. Recognizing the challenges presented by large class sizes and Teaching Assistants' limited teaching experience, how can we effectively employ graduate students as Teaching Assistants to enhance undergraduate learning in engineering? This paper provides details on the approach taken by Memorial University to support Teaching Assistants as educators and to draw on their experience and enthusiasm for engineering education. It also examines the approach taken in one undergraduate engineering course to engage Teaching Assistants with the content, the students, and the professor.
\end{abstract}

\section{Introduction}

Teaching assistants (TAs) provide essential support roles in the co-ordination of large undergraduate classes, but are often overlooked in discussions of pedagogy, both as aspiring teachers and as continuing learners [1], [2]. Using a case study approach and the principles of "student-centred learning," this paper will examine the TA experience and best practices related to TA training as they pertain to a large undergraduate engineering course with a non-technical focus.

ENGI 3101 "The Engineering Workplace" is a second-year, mandatory "complementary studies" course for engineering students in all disciplines in the Faculty of Engineering at Memorial University. In addition to a fourth-year companion course, known as ENGI 7102 "The Engineering Profession," ENGI 3101 covers areas in professionalism, communication, and ethics with the intent of helping students develop competence in higher-order, process-oriented skills (sometimes called "soft" skills). ENGI 3101 and 7102 are intended to enrich the student's understanding of the profession, not only in terms of the standard obligations placed upon the engineer to uphold the health, safety, and wellbeing of the public, but also in terms of the profession's growing sense of its broader social responsibility in an era of complex and interrelated global challenges, as exemplified in [3][9]. Both courses also focus on cultivating students' individual sense of professional identity through reflective activities designed to connect theories and principles with students' own experience.

Because ENGI 3101 is foundational and mandatory, class sizes are large; course enrolment is usually between $220-250$ students, and the class is divided into two sections with the same instructor teaching both sections. Classes meet twice a week for 75 minutes. While earlier versions of the course were mainly lecture- and exam-based, ENGI 3101 has been subject to ongoing redesign since 2011, experimenting with alternative assessment models such as reflective assignments, team projects, and in-class writing prompts. The purpose of this course redevelopment is to align its content and delivery more effectively with $\mathrm{CEAB}$ graduate attributes, to emphasize the ongoing integration of technical and non-technical professional skills in undergraduate engineering, and to promote a more active and student-centred model of teaching and learning.

Prior versions of ENGI 3101 covered topics such as workplace and professional ethics, gender, diversity, and equity, technical communication, occupational health and safety, and engineering impacts on society. While all of these topics are still included as course 
content, the redesign process involved the current instructor (Rosales) adopting student-centred learning models and developing specific learning outcomes through consultation with a number of faculty and staff both inside and outside the Faculty of Engineering, including those with extensive backgrounds in instructional design and experiential learning. Following are the competencies that students are expected to develop upon completion of ENGI 3101:

- Identify the range of skills required to be a successful engineer;

- Apply the principles of critically reflective practice to their own professional growth and development in relation to the standards of professional engineering conduct;

- $\quad$ Evaluate the validity of information sources and adequately document their research sources;

- Communicate technical information in a clear, effective, and professional manner using oral, written, and graphic delivery methods;

- Understand and practice the principles of academic and workplace integrity;

- Discuss the ethical responsibility of professional engineers, as employers and employees, with respect to Occupational Health and Safety legislation as well as the Engineering Code of Ethics;

- Apply the concepts of ethics, diversity, fairness, and equity to professional engineering scenarios and case studies;

- Explain and apply strategies for ethical problem-solving;

- Identify and evaluate their own performance and the performance of others in a team setting, using a variety of team-effectiveness inventories and exercises.

Hallmarks of student-centred learning (SCL) include hands-on experience, time to reflect about that experience, establishing a personal connection to the material, meaningful application of knowledge and skills, and oftentimes a sense of personal transformation [10]-[13]. ENGI 3101 was designed to provide these types of opportunities for students, and the learning outcomes were made explicit. Instructional staff are now assessing the impact of this shift to student-centred learning through course evaluation, staff debrief, personal reflection by the instructor, and collegial conversations about effective pedagogy.

However, rather than address the impact of SCL on the undergraduates in ENGI 3101, the intent of this paper is to argue that there actually should be two levels of intention in student-centred course design: one focused on the undergraduate experience and the other mindful of learning opportunities for graduate teaching assistants. This paper will focus on the argument that teaching assistant (TA) development can and should benefit from the design principles of student-centred learning, both in terms of cultivating the TA's own professional development and in terms of broadening the TA's understanding of effective teaching practice. In short, if the hallmarks of studentcentred learning involve lived experience, reflection, personal connection to the material, meaningful application of skills, and even personal transformation, then we argue that some or all of these hallmarks could also be applied to the teaching assistants' learning experience with the course. TAs who benefit from a SCL experience are able to be active, participants in undergraduate SCL. They can contribute to the development of graduate attributes in undergraduate engineering students in an effective and impactful way. This effective use of TAs enhances the teaching and learning for the TA, the undergraduate and the faculty member.

In typical undergraduate engineering courses, teaching assistants may grade exams and mark assignments, often anonymously, and often with no other contact with students or other teaching assistants. Those who run tutorials or assist with labs often have better opportunities to interact with students and to gain more valuable experience in an instructional role, and some teach entire classes as a substitute for the regular instructor, but often there is little formal instructional training provided for a graduate student who has been assigned TA duties. While many universities do offer instructional development and professional development programs to faculty and graduate students, the offerings are usually subscribed to on a voluntary basis.

At Memorial University, engineering graduate students are required to complete a one-day intensive introduction to the duties of a TA. This program includes an overview of roles and responsibilities of TA's, instruction on dealing with students, how to deal with conflict, an introduction to marking strategies, and a brief discussion on how to create a safe learning environment. Additional training is available on a voluntary basis through a non-credit, certified "Teaching Skills Enhancement Program (TSEP)" program. It is up to the graduate student to apply this learning, both required and voluntary, in his or her teaching assistantship. Using a case study model, this paper will explore one teaching assistant's experience in a course that strove to provide a learning environment for the graduate assistant, engaging them in the SCL experience of the undergraduate students, while providing an opportunity for gainful employment. 


\section{Teaching Assistants in Student-Centred Leaning: A Case Study}

With the learning outcomes for ENGI 3101 focused on developing higher-order professional skills such as effective communication, professional self-awareness, and ethical reasoning, the course assessments were designed to support those outcomes, according to the principles of constructive alignment [14], [15]. Because evaluating these types of skills often requires qualitative feedback and a certain amount of subjective judgment, and because a large class setting means that no single person can deliver specific and timely feedback to every student, it was essential that the course could avail of a competent team of teaching assistants to evaluate both the technical and reflective components of the assignments.

The instructor purposely chose a teaching assistant team that would combine personnel who had an engineering background with those who came from non-engineering backgrounds. Previous "nonengineering" TAs for ENGI 3101 have come from Anthropology, Biology, English, Religious Studies, Sociology, and an interdisciplinary graduate Humanities program. In addition to demonstrating proficiency in writing, a reliable work ethic, and a willingness to explore another discipline, the criteria for selection focused on the teaching assistant's interest in helping students think and write clearly, to develop professional conduct, and to understand the social, ethical, and environmental impacts of engineering decisions. The rationale for creating a mixed-discipline team ${ }^{1}$ was twofold: the undergraduate students taking the course needed to gain experience communicating engineering concepts to a non-specialist audience (as they would be called upon to do regularly later in their profession, whether for clients, supervisors, or the public) and the TAs themselves would develop their own transdisciplinary professionalism through working as members of a course management team. Both Fall 2011 and Fall 2012 versions of the course employed six teaching assistants.

A teaching assistant orientation meeting at the start of the course set the tone for building the team. Here the instructor outlined not just the duties expected of the TAs but also what the TAs could expect to get out of the experience for their own professional development. The meeting helped to frame the

\footnotetext{
${ }^{1}$ In reality, even the Engineering TAs themselves could be considered to constitute a mixed-discipline team, given the Faculty's disciplinary specialties in Civil Engineering, Ocean \& Naval Engineering, Process Engineering, Mechanical Engineering, Electrical Engineering, and Computer Engineering.
}

CEEA13; Paper 69

Montreal, QC; June 17-20, 2013 experience as a learning opportunity for the graduate students; in the context of graduate student training, the ability to identify and document specific skill development is increasingly important for building documents such as a teaching dossier. Team members explained their own academic and professional backgrounds, which also helped establish some foundation for potential future networking.

The teaching assistants introduced themselves to the class in the early days of the course so that they could establish a measure of accountability in their subsequent interactions with the students, instead of remaining anonymous markers. In addition, TAs would sign off on their comments on student work throughout the term so that the student could more effectively address their comments and questions about assignments. Anecdotally, the instructor reports that it became less necessary to intervene in clarifications and questions about grading, once the TAs established a practice of signing their feedback.

Because student-centred learning models strive to establish clear expectations and goals during assessment [16], [17], grading rubrics were prepared and made available to both students and TAs in advance of assignment deadlines. TAs were asked for their feedback on the rubric's effectiveness both as they used the instruments as well as at a debrief session at the end of the term. In addition, students expressed satisfaction with knowing what specific criteria would be evaluated, particularly since the assignments were designed for qualitative, rather than quantitative, assessment.

Because the ENGI 3101 teaching assistants' main duties involved grading student assignments, the initial team meetings focused on building consensus. As with any type of qualitative - and to some degree, subjective-analysis, the team needed to establish what is often known as "inter-rater reliability", see [18], [19] for example. Inter-rater reliability refers to the degree of consistency achieved between multiple evaluators of a single work. The first marking meeting involved the TAs and instructor using the rubric to mark a small selection of assignments independently and then to compare results. Although the instructor gave guidance about what constituted a reasonable grade, she also emphasized the ownership that each TA should cultivate over his or her work, and asked the graders to justify why they assigned the mark that they did in each case. Some examples yielded comparable results but where there was greater disparity in grading, the opportunity for the TAs to explain their own rationales helped the TAs to clarify their own approach and to compare their evaluations to those of their colleagues. In an environment where it is still common for TAs simply to be anonymous, 
solitary markers with no contact with the students, this approach ensured that there was more accountability both for the graduate students providing feedback and for the undergraduate students seeking fair and constructive evaluation.

Subsequent TA meetings throughout the term continued to address issues around inter-rater reliability as well as to get feedback on the course from the TAs' perspectives, particularly concerning what was working well in the assignments and what could be improved.

In the case of ENGI 3101 the role of the TA was more limited than for its companion course, ENGI 7102, where TAs have more prolonged and personal contact with students through class discussion and team project consultations. In 3101 the TAs did mainly serve as graders, and there is certainly room to expand their contribution to the course. For example, TAs were welcome to attend the lectures and to participate in periodic short class discussion, particularly to share their own stories from the engineering workplace (or from workplaces in general), but attendance was not mandatory. Given the extra time demand this places on the TA's limited assigned hours, only one of the six TAs availed of the invitation, but it was evident that her participation in class discussion helped students better understand the relevance of particular lecture concepts to "real-life" professional contexts.

Although this case study is quite limited in its scope and intent, we believe we can point towards some best practices in student-centred learning and apply it towards graduate student mentorship and training.

1. Build a sense of community and respect: For a team of teaching assistants in a large class context, it is often easy to treat course administration and learning as assembly-line work. Taking time at the start of the course to establish a sense of collegiality between TAs and to recognize the motivations, experiences, and expectations of the students who will be submitting work helps to humanize and personalize the TAs' interactions with students and student material. Establishing this kind of environment becomes particularly important when students need to receive constructive, qualitative feedback on assignments that ask for subjective responses.

2. Acknowledge that learners are not empty vessels: Student-centred learning acknowledges that students bring their own experiences to a course, and learn in a variety of ways. Training teaching assistants to recognize and value that diversity not just in the classroom but also amongst

CEEA13; Paper 69 -4 of $6-$ their colleagues will encourage them to develop a variety of techniques to become effective communicators both in the classroom and in the broader workplace. Likewise, teaching assistants often bring a rich academic and professional background with them which can be used to engage students in course material, such as inviting TAs to participate in a class discussion about workplace ethics and to contribute learning moments from their own employment experiences.

3. Help to facilitate, rather than direct: In student-centred learning, the instructor becomes more of a guide or facilitator rather than a singular leader; when employing TAs in such an environment, the instructor extends greater autonomy and accountability to the TA and creates opportunities for TAs to have input into some of the decisions around the course, such as suggesting adjustments for assignment rubric criteria and weighting to more effectively evaluate student work. While there will always be situations where the instructor makes the executive decision, there may be opportunities to build consensus and promote a feeling of shared investment in course outcomes.

4. Define clear goals and expectations: Both students and teaching assistants should be aware of the standards towards which they should strive and against which work will be measured. Establishing benchmarks such as learning outcomes and grading rubrics helps to clarify expectations on behalf of both student and evaluator.

5. Adopt an attitude of life-long learning: Graduate training and mentorship by their very nature emphasize the need to keep one's skills and knowledge current but student-centred learning environments tend to promote this focus even more emphatically. Recognizing that today's constantly changing workplace demands adaptability and resilience, instructors can encourage teaching assistants to serve as professional development exemplars for undergraduate students and for each other.

\subsection{The Teaching Assistant Perspective}

Susan is a doctoral candidate in engineering who is interested in pursuing a career in academia and is particularly interested in engineering education. She had a successful career in the automotive industry and is a licensed professional engineer. As a professional

Montreal, QC; June 17-20, 2013 
engineer with experience in hiring and mentoring new graduates, she had a particular interest in becoming a TA for ENGI 3101 The Engineering Workplace. In her experience, new graduates face many challenges as they integrate into the workforce and the profession. She found the opportunity of becoming a TA for ENGI 3101 and helping students develop the skills they need to overcome these challenges very appealing.

Susan considered the initial meeting with the other ENGI 3101 TAs as an indication of the unique approach the faculty member was using to integrate teaching assistants into an engineering course. This meeting helped facilitate comradery between the many TA's, introduced them to the subject and to their role in the course. Other experiences have not been as structured and contact with other TA's has been limited. Other than this experience, Susan had never had an instructor discuss and explain the specific expectations and importance of her role as a TA. Because of this inclusion, a sense of responsibility was fostered. The instructor's respect for opinions and genuine interest in feedback from the TA's indicated to Susan that her role was important to both the instructor and to student learning.

In subsequent meetings, the importance of the role of TAs in the course was further demonstrated. For example, one meeting was held to ensure consistent marking for all TAs. The instructor assigned three assignments for assessment that all TAs were asked to mark using the same rubric. They met to discuss how each person (TAs and Instructor) assessed the student's work. Marks for each category were discussed in turn and reasons for each mark were discussed. Susan felt this exercise was beneficial and she was confident that she was able assess student work in a fair manner consistent with the course expectations. She also learned the importance of consistent marking and the use of rubrics and an assessment tool. She gained the skills needed to develop a strategy to help ensure consistency in assessment as she goes on to TA in other courses.

These TA meetings increased Susan's enthusiasm for, and engagement in, her duties as a TA. Meetings always consisted of solicited feedback and discussion of issues, possible solutions and suggestions for improvement. This level of engagement indicated that opinions of TAs were important and valued, translating into a desire to do the best possible work for both the instructor and the students.

The instructor emphasised the importance of feedback to student learning. She required that all work have comments included on assessments to help students understand their marks and how to improve their work. She also requested that all TAs sign their CEEA13; Paper 69 Montreal, QC; June 17-20, 2013 work and act as the first contact for student questions on assignments. This indicated to Susan that the instructor had confidence in her ability to assess student work and to deal with student issues. It also increased her attention to the quality of her work so that she could justify her decisions.

Although it was not required, Susan attended the majority of the lectures for this course. This was initially for two reasons: to learn new teaching strategies and techniques from the instructor and to ensure that she understood the course material and expectations to improve the quality of her marking and feedback. After attending a few lectures, Susan also had the opportunity to participate in class discussions and help facilitate lectures. Her experience and opinions were well received by the instructor and the students. She felt she was making a valuable contribution to the course and to the students' education.

Susan feels this experience was unique. She has had no other TA experience that gave her such an indication of her importance to the students' learning or that taught her so much about teaching, learning and professionalism. Susan has already applied some of the skills she learned to other TA experiences. As an example, she has successfully developed and used rubrics to ensure consistent marking for students and applied some of the group discussion techniques learned from observing the instructor to facilitate small group discussions.

\section{Conclusion}

In this paper we have examined the role that student-centred learning and instructor mentorship can play in the professional development of graduate student teaching assistants. While the techniques and recommendations should not come as a surprise, we do believe that more mindful and purposeful interaction between TAs and course instructors can help to enrich and enhance the learning environment both for the students who take the course and the graduate students who help facilitate the course.

While we do not seek to be prescriptive about whether engineering educators should adopt SCL models across the board, we do however suggest that there are ways that faculty who are interested in SCL models can incorporate that approach into their training and mentorship of TAs. On the one hand, graduate students play an instructional role providing assignment guidance and feedback as teaching assistants, but on the other, they are themselves learning both implicitly and explicitly about professionalism and pedagogy. Regardless of whether 
these students choose a career in academia or elsewhere, teaching assistantships that are designed to address aspects of professionalism and pedagogy can provide valuable potential to develop skills that are considered employable, transferable, and appropriate for those considered to be "highly qualified personnel", i.e. people with advanced degrees in higher education, often in professional fields (e.g. teachers, engineers, physicians, etc.) [20].

Designing a TA experience to include the hallmarks of student-centred learning may then result in more engaged students, more engaged teaching assistants who develop professional and transferable skills, and perhaps even more fulfilment - and less work - particularly for professors who teach large classes.

\section{References}

[1] L.D. Sargent, B.C. Allen, J.A. Frahm and G. Morris, "Enhancing the experience of student teams in large classes: Training teaching assistants to be coaches, in Journal of Management Education 33:5 pp 526-552, Oct. 2009.

[2]W. L. Harkness and J. L. Rosenberger, "Training graduate students at Penn State University in teaching statistics," in The American Statistician, Vol. 59, No. 1 (Feb., 2005), pp. 11-13

[3] D. Douglas and G. Papadopoulos with J. Boutelle, Citizen Engineer: A Handbook for Socially Responsible Engineering, Prentice Hall, Upper Saddle River, NJ, 2010.

[4] C. Baillie, "Engineering and society: Working towards social justice part I: Engineering and society", Synthesis Lectures on Engineers, Technology, and Society \#8, C. Baillie, Ed. Morgan \& Claypool 2009.

[5] National Academy of Engineering, The Engineer of 2020: Visions of Engineering in the New Century, Report of a Committee Part 1, National Academies Press, Washington, DC, 2004

[6] National Academy of Engineering, Educating the Engineer of 2020: Adapting Engineering Education to the New Century, National Academies Press, Washington, DC, 2005.

[7] D. Riley, "Engineering and social justice", Synthesis Lecture on Engineering, Technology, and Society \#7, C. Baillie, Ed. Morgan \& Claypool, 2008

[8] D. Grasso, M.B. Burkins, J. Helble, and D. Martinelli, "Dispelling the myths of holistic engineering", Holistic Engineering Education: Beyond Technology. D. Grasso \& M. B. Burkins, Eds. Springer, New York, 2010, pp. 159-165. CEEA13; Paper 69 -6 of $6-$
[9] D. Grasso and D. Martinelli, "Holistic Engineering", The Chronicle Review, vol. 53, no. 28, March 16, 2007, p. B8.

[10] J.E. Stice, "Using Kolb's Learning cycle to improve student learning", Engineering Education, vol. 77, no. 5, pp. 291-96, Feb. 1987

[11] R.B. Barr and J. Tagg, "From teaching to learning: a new paradigm for undergraduate education", Change, vol. 27 , no. 6, 1995. Available from http://www.tandf.co.uk/journals/VCHN

[12] L.D. Fink, Creating Significant Learning Experience: An Integrated Approach to Designing College Courses, San Francisco: Jossey-Bass, 2003.

[13]M. Weimer, Learner-Centred Teaching: Five Key Changes to Practice, San Francisco: Jossey-Bass, 2002.

[14] J. Biggs, "Enhancing teaching through constructive alignment", Higher Education, vol. 32, no. 3, 347-364, Oct. 1996.

[15] J.B. Biggs, Teaching for Quality Learning at University: What the Student Does, Philadelphia: Open University Press, 1999.

[16] M.E. Huba and J.E. Freed, Learner-Centered Assessment on College Campuses: Shifting Teaching to Learning, Needham Heights, MA: Allyn \& Bacon, 2000.

[17] K. Montgomery. "Authentic tasks and rubrics: Going beyond traditional assessments in college teaching." College Teaching, vol. 50, no.1, Jan. 2003.

[18] J.A. Newell, K.D. Dahm, and H.L Newell, "Rubric development and inter-rater reliability issues in assessing learning outcomes, in Proceedings of the 2002 American Society for Engineering Education Annual Conference \& Exposition, 2002.

[19] J.A. Preston and R. Shackelford, "Improving on-line assessment: An investigation of existing marking methodologies, in ACM SIGCSE Bulletin, vol. 31, no. 3, pp. 29-32, Sep. 1999

[20] D. Colardyn, Continuing Professional Education of Highly-Qualified Personnel, Organization for Economic CoOperation and Development, OECD Publishing, Sep. 1995.

Montreal, QC; June 17-20, 2013 